\title{
The degree of restoration of the soil properties developed under the fallows in the early stages of succession
}

\author{
$D A$ Filimonova $^{1}, S V$ Solovev $^{1, *}, A N$ Bezborodova $^{1}$, and $G F$ Miller $^{1}$ \\ ${ }^{1}$ Institute of Soil Science and Agrochemistry, Siberian Branch of the Russian Academy of Sciences, \\ 8/2, Ac. Lavrentieva ave., 630090, Novosibirsk, Russia
}

\begin{abstract}
At present, the return of fallow lands to agricultural circulation is an important and one of the topical issues of the whole world. Research related to the restoration of soil properties of fallows is of particular value. Therefore, it is necessary to know what processes occur in the vegetation and soil cover of fallows at the different stages of their development, taking into account local natural features. The paper presents the results of a survey of young (up to four years) and middle-aged (up to ten years) fallows of the forest-steppe zone of Western Siberia within the Novosibirsk region. It is established that in the first decade of succession in fallow areas there are two stages of overgrowth, and when analyzing the structure of plant matter, it is shown that the ratio of their fractional composition reflects the general tendency to restore the ecosystem that preceded plowing. Restoration of soil properties under young and middle-aged fallows is much slower. Data of humus content analysis allow us to conclude that its content is somewhat higher in the upper parts of the profile in middle-aged fallows compared to young fallows. The research on soil-physical characteristics and vegetation cover allowed us to note the trends of restoration of the initial state of soils.
\end{abstract}

\section{Introduction}

The process of cultivation of the soil is accompanied by the process of removing parts of agricultural land from circulation (by transferring them to the fallows). Such lands are of interest, because they are the economic and environmental reserves of Russia and the whole world [1-3]. Abandonment of agricultural land is common in Europe, especially in postsocialistic countries [4] and the returnig of the fallows into agricultural use is very appropriate for the effective use of agricultural land.

However, there is a process in which, during a long use of the soil as the crops, the ecosystem changes significantly. In particular, seeds of weed and ruderal species replacing seeds of native species, the arable horizon is formed in the soil. The physical, chemical properties and microbiological composition of the soil also are changed [5]. When the arable land becomes fallow land, the conditions in the biocenosis also change, for example,

\footnotetext{
*Corresponding author: solovyev@issa-siberia.ru
} 
the gradual overgrowing with native species takes place $[5,6]$. On the other hand, the process of returning fallows into the active agricultural use may lead to imbalance between the processes of humification and mineralization which is the cause of the loss of the organic matter and the infringing of the biological interchange of the matter [7]. Therefore, when the arable land turns into the fallow land and in the reverse process of returning fallows into the arable lands it is necessary to take into account the whole range of regional characteristics of the territory.

\section{Materials and methods}

The study area is located in the Novosibirsk region. - as of 01.01.2016 fallow lands are equal to 81 hectares of land [8], which is $0.7 \%$ of the total area of agricultural land. However, this factor does not reflect the true state, because, in the past decades practice, it often happens that the abandoned land is transferred to other categories of land (pastures or hayfields, for example).

The identification and age determination of the fallows were conducted using the analysis of the cartographic material of different ages, including GIS, surveys of the officials and the local residents. Also, determining the time which soil spent in a state of fallow was carried out according to the methodology developed at the Institute of soil science and Agrochemistry SB RAS [9]. It should be noted that the detection of fallows of different ages is quite difficult, and it is merely impossible to find fallows of the same age formed under the same conditions. In addition, the hay blocks the development of succession, returning it back to the previous stage of overgrowth [6].

The study area belongs to two neighboring geomorphological regions. The first one is hilly high plain of Bugotak and the second one is Cherepanovskiy high sloping erosional plain located in the Eastern part of the Novosibirsk region. These regions are separated by a valley of river Berd (the right-hand tributary of the $\mathrm{Ob}$ river). The study area lies within the forest-steppe province of leached chernozem, podzol and grey forest soils [10]. According to the climatic zoning, the study area is located within a temperate-continental climate. Studied soils are formed mainly under the influence of woody (small-leaved) and grassy (meadow) vegetation, resulting in the formation of chernozem and gray forest soils [11-12].

The objects of study were the agricultural lands, which had been ploughed up until 2014-2015. At the time of the study they were in a state of fallow no more than 3 years. The soil profiles and geobotanical sites were laid out in Iskitim district of Novosibirsk region: 1) near the Alexandrovsky village - the fallow age of 2-3 years, the soil is leached medium-eroded chernozem, 2) near the Morozovo village - the fallow age of 3-4 years, the soil is dark-grey forest soil 3) near the Ust-Kamenka village - the fallow age of 6-7 years, the soil is leached chernozem; 4) near the Ulybino village - the fallow age of 7-10 years, the soil is leached chernozem. For the detection of changes in soil properties that occurred after the cessation of plowing, the properties of arable soils of the studied analogues of fallows were examined: on the leached medium-eroded chernozem; and on the dark gray forest.

The study of vegetation was carried out in accordance with standard approaches, the analysis of square projective cover and species richness of plant communities was defined on the area of $1 \mathrm{~m}^{2}$ in triplicates.

In conducting research for the study of agro-physical properties of soils of fallow lands the following methods were used: determination of granulometric composition by sievepipette method [13]; determination of organic carbon (humus) by Tyurin [13]; determination of soil $\mathrm{pH}$ by the potentiometric method [14]. 


\section{Results and discussion}

The 2-years old fallow located near the Alexandrovsky village has a plant cover, comprising 21 species, and mostly represented by dominant ruderal species: Euphorbia virgata, Sonchus arvensis, Linaria acutiloba, Avena fatua. Also, there were noted such species as the Lactuca serriola, Conyza canadensis, Cirsium setosum, etc. The total projective cover is $70 \%$. The proportion of young plants is $29 \%$; the proportion of perennial species is $71 \%$. Green phytomass is equal to $467.3 \mathrm{~g} / \mathrm{m}^{2}$, and above-ground mortmass is equal to $115.0 \mathrm{~g} / \mathrm{m}^{2}$. According to the methodological manual for age determination of the fallows [9], the research object is in a fallow state for less than two years.

The soil cover of this area is represented by medium-eroded leached chernozem located on a gentle slope South-Eastern exposure.

As noted above, the additional soil profile and geobotanical site was laid on the arable land for the comparison near the studied fallows, the same type of soil. Vegetation is represented by crops of Triticum aestivum and four weed species: Convolvulus arvensis, Panicum miliaceum, Sonchus arvensis and Euphorbia virgata. Green phytomass is equal to $287.0 \mathrm{~g} / \mathrm{m}^{2}$, and above-ground mortmass is equal to $160 \mathrm{~g} / \mathrm{m}^{2}$. However, it should be noted that the field was treated with herbicides and the weeds were in an extremely depressed condition.

The area of fallows the age of 3 years near the village of Morozovo has a plant cover, comprising 23 species, mainly represented by the following dominant species: Cirsium setosum, Vicia cracca, Sonchus arvensis, Equisetum arvense, Melilotus officinalis, Elytrigia repens. The coverage is $90 \%$. The proportion of young plants is $13 \%$, the proportion of perennial species is $87 \%$. Green phytomass is equal to $665.1 \mathrm{~g} / \mathrm{m}^{2}$, and aboveground mortmass is equal to $255.4 \mathrm{~g} / \mathrm{m}^{2}$. According to the methodological manual for age determination of the fallows [9], the object of study is fallow and not more than three years, the stage of overgrowing - transition from pioneer to intermediate. Plowing vegetation is represented by crops of Fagopyrum esculentum and 11 weed species: Panicum miliaceum, Triticum aestivum, Convolvulus arvensis, Tripleurospermum inodorum, etc. Green phytomass is equal to $228.9 \mathrm{~g} / \mathrm{m}^{2}$, and above-ground mortmass is equal to $25 \mathrm{~g} / \mathrm{m}^{2}$.

The soil cover of this area is represented in dark-grey forest medium loamy soils. Close to the fallows, on the arable part of dark gray forest soil, the soil profile cut was also laid. Both profile cuts were located on the North-Northwest-faced gentle slopes with depressions.

The 6-7 years old fallow developed on leached chernozem near the Ust-Kamenka village has a vegetation cover of 29 species and is mainly represented by the following dominant species: Elytrigia repens, Dactylis glomerata, Achillea asiatica, Artemisia vulgaris, Vicia cracca and Phleum pratense. The total projective cover is $95 \%$. The proportion of young plants is $3 \%$, and the proportion of perennial species is $97 \%$. Green phytomass is equal to $560.2 \mathrm{~g} / \mathrm{m}^{2}$, and aboveground mortmass is equal to $601.4 \mathrm{~g} / \mathrm{m}^{2}$.

The 7-10 years old fallow developed on leached chernozem near the Ulybino village has a vegetation cover of 24 species and is mainly represented by the following dominant species: Dactylis glomerata, Bromopsis inermis and Calamagrostis epigeios. The total projective coverage is $95 \%$. The proportion of young plants is $8 \%$, the proportion of perennial species is $92 \%$. Green phytomass is equal to $511.8 \mathrm{~g} / \mathrm{m}^{2}$, and aboveground mortmass is equal to $632.7 \mathrm{~g} / \mathrm{m}^{2}$.

When comparing the vegetation cover of the studied fallows of different ages, regular processes are observed. As the age of the fallow increases, the total number of species also increases, including the proportion of perennial species, while the proportion of annual and biennial plants decreases. On the fallows up to 6 years old, an increase in total aboveground production is observed, and concerning the mortmass the same pattern is observed. 
However, it should be noted that green phytomass reaches its maximum values on fallows aged 3-4 years, most likely, this is due to the fact that these fallows are in the transition from pioneer to intermediate stage and there is a change in species composition (fig. 1). Characteristic parameters of the structure of plant matter, which are used to assess the functioning of ecosystems, are the indicators of the ratio of parts of the plant substance, for example, the ratio of green phytomass and dead grass and plant litter reflects the ratio of the speeds of formation of aboveground phytomass and its extinction.

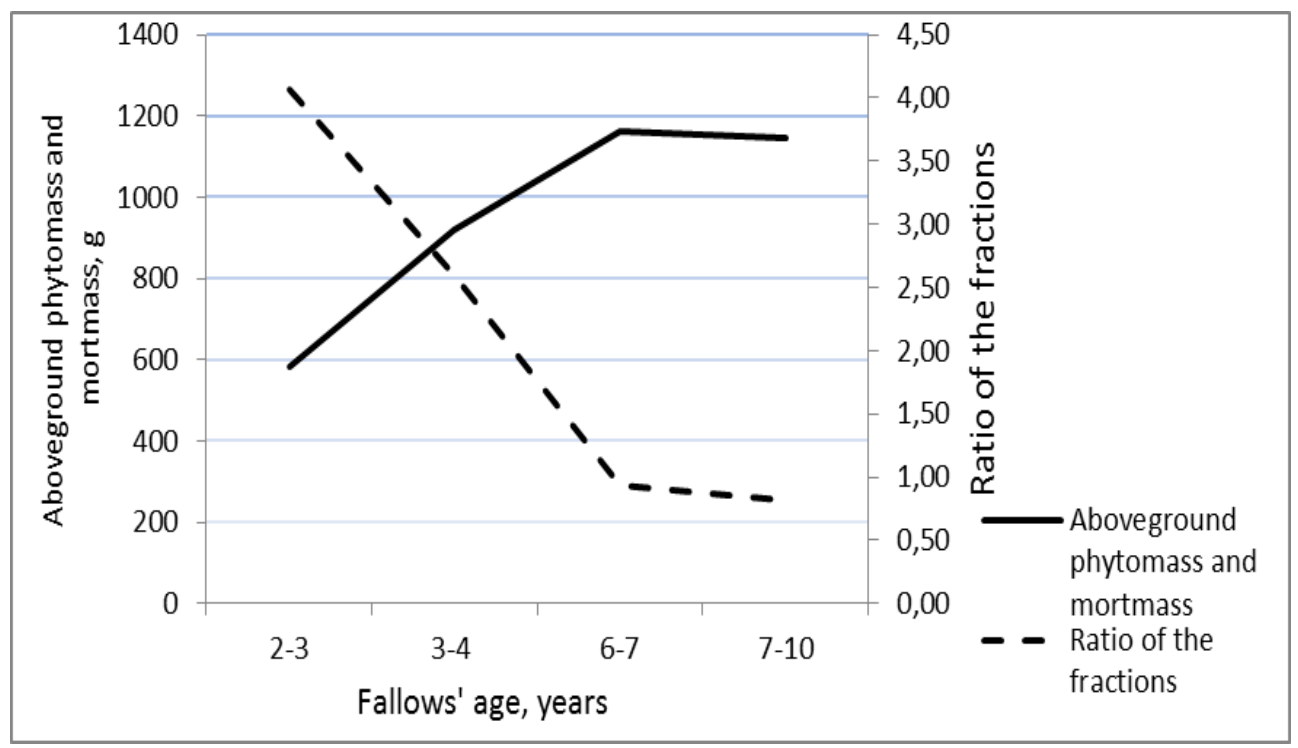

Fig. 1. Trends in aboveground production in young and middle-aged fallows.

As shown in figure, with increasing age of the fallow the ratio of green phytomass and mortmass fractions decreases sharply, starting from 6-7 years, which indicates significant changes in the structure of the plant cover due to the intensive accumulation of mortmass. In the same time green phytomass gradually comes into balance with the environment.

Pairwise (arable land, fallow) comparative analysis of the properties of soils of the same genesis was held. When examining analytical data obtained in laboratory studies of samples, the expected shift of the values of indicators of soil properties in the dark-grey forest soils are revealed. In the chernozems such shifts are not revealed, which, in our opinion, is due to the very short period during which soil stayed under the fallows.

It should be noted that, as on gray forest soils and chernozems, which are developed under fallows, a plant litter layer (in spite of the ongoing process of succession) is not formed. This is due to the short period of developing of soil under the fallow. With regard to physical and chemical changes in grey forest soils and chernozems: dark gray forest soils developed under a fallow age of 3 years, despite the brief staying in the state of fallows, revealed the return of a soil in a slightly acid condition. The same type of soil developed under the arable land has a slightly alkaline reaction. In addition, the content of humus in the layer of $0-20 \mathrm{~cm}$ and $20-30 \mathrm{~cm}$, in this type of soils under the young fallow, is, albeit slightly, but large.

A pairwise comparison of an middle-aged fallow with the corresponding arable land and a young-aged fallow with the corresponding arable land allowed us to draw the following conclusions: the $\mathrm{pH}$ change with the transition of arable land to the fallow land is insignificant in both cases (the difference between the $\mathrm{pH}$ is from 0 to 0.4 ) and is within the neutral reaction. In addition, there is a tendency to increase the acidity in the upper $20 \mathrm{~cm}$ 
of the soil with the fallow's age increment. This may be due to the gradual accumulation of plant residues (plant litter) (fig. 2).

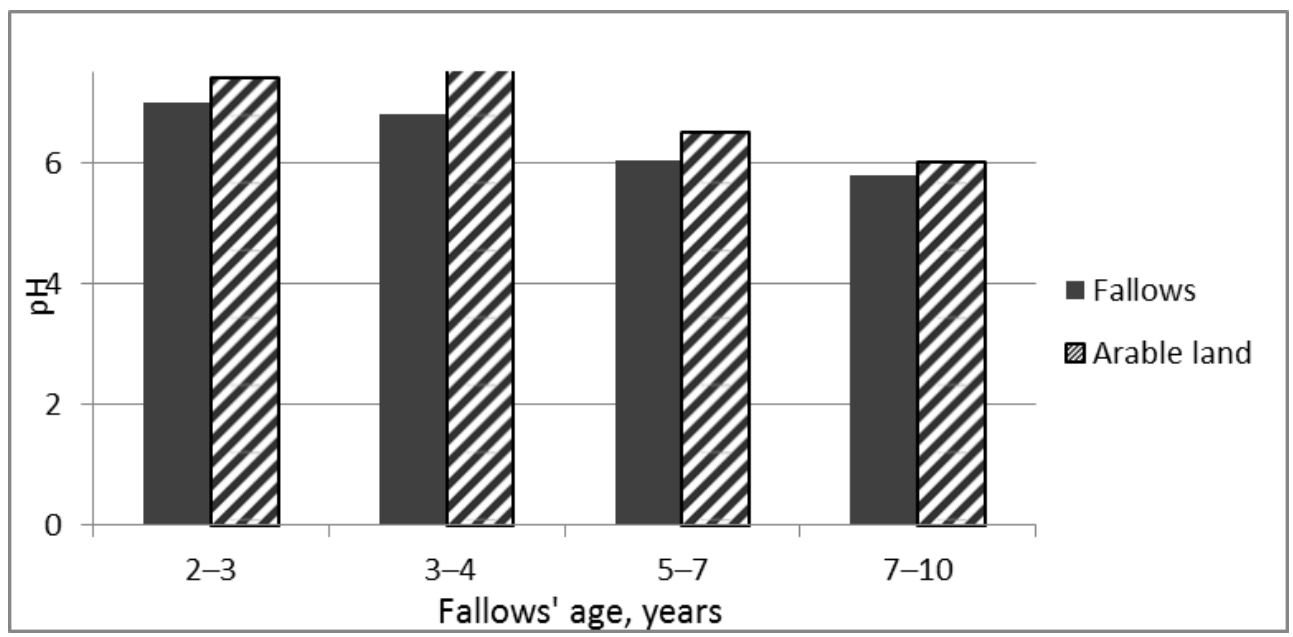

Fig. 2. $\mathrm{pH}$ in the upper $20 \mathrm{~cm}$ of fallows and corresponding arable lands.

The restoration of the physicochemical properties is not detected in the leached chernozems under young age fallows. The humus content in the layer $0-20 \mathrm{~cm}$, in this case, was somewhat greater in the arable land. But keep in mind that this can be explained by the presence or absence of agrochemical in both cases, during the previous years.

The study of humus content allowed us to conclude that it is slightly higher in the upper parts of the profile in fallows aged 7-10 years compared to fallows aged 2-3 years $(5.62 \%$ and $5.5 \%$, respectively), with a noticeably sharper decrease in its content down the profile. This may be due to the return of the soil to its original humus state, starting from the upper horizons due to the restoration of vegetation cover and the formation of plant litter (fig. 3).

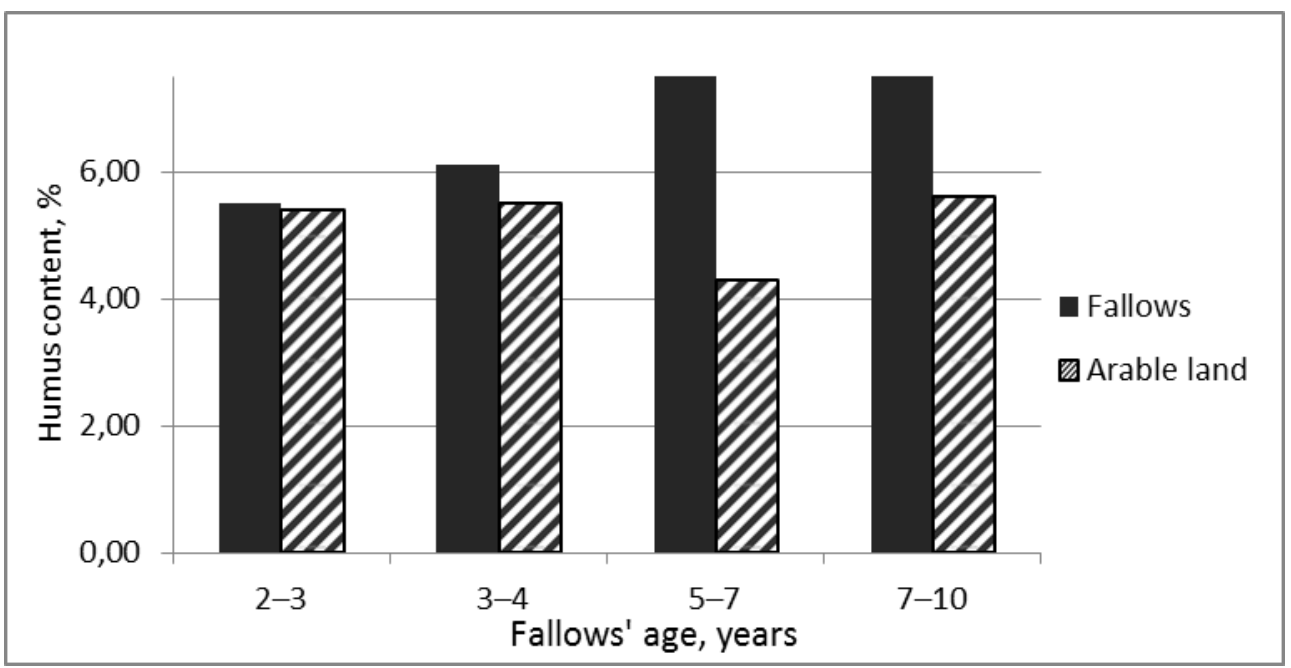

Fig. 3. Humus content in the upper $20 \mathrm{~cm}$ of fallows and corresponding arable lands.

With increasing age of the fallows the differentiation of an arable layer is observed: the bottom part continues to be more dense compared to the upper part, penetrated by root systems. Thus, the upper part of the former arable layer reacts more strongly to the changes 
in plant composition and quickly returns to a state close to the original, which is confirmed by the study [15].

Studying the granulometric composition, special attention was paid to the clay fraction, as the most labile component, which reacts most strongly to changes in environment. Based on the figure (fig. 4), we can note a decrease in the content of clay particles in fallows of different ages compared to the corresponding arable lands. At the same time, it should be noted that there is a higher content of clay particles in the upper horizons of the fallows aged 7-10 years, compared to the young fallows ( $16.60 \%$ and $6.68 \%$, respectively). Due to the inability to determine the state of the soil during its transition to the fallow, in particular whether it was depleted of clay particles, we suggest caution in assuming how much the content of the clay fraction has changed over time.

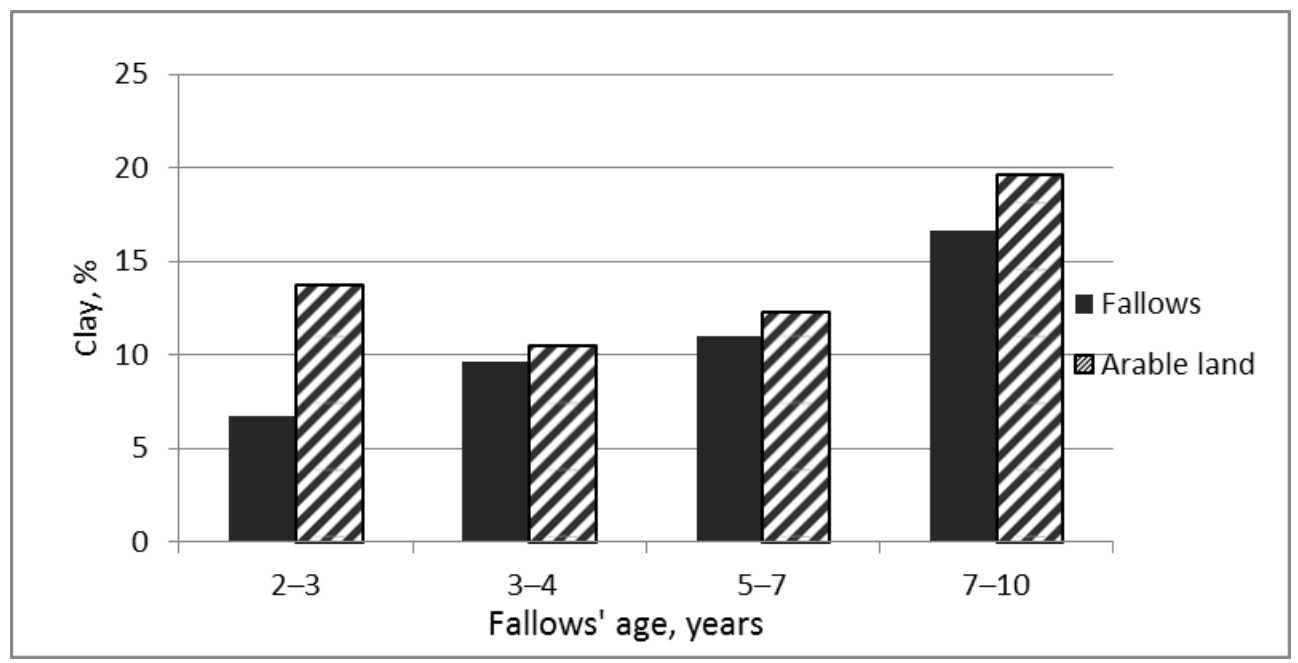

Fig. 4. Clay fraction in the upper $20 \mathrm{~cm}$ of fallows and corresponding arable lands.

\section{Conclusions}

Based on the above evidence, it is possible to draw the following conclusion. At the transition of arable land in the fallows during the first two years there is an active colonization of arable weed species. In the following year there is a transition to the intermediate stage characterized by colonization of the territory by the Elytrigia repens. Soils of different genetic types (chernozems and gray forest soils) which are developed in the same natural setting under the fallows do not have any significant morphological and physicochemical changes in such a short time.

Analyzing the structure of plant matter, it was noted that the indicators of the ratios of their fractional composition reflect the general trend toward the formation of the ecosystem preceding plowing.

The analysis of changes in the soil and vegetation cover of young and middle-aged fallows allows us to conclude that these lands are gradually returning to a state of equilibrium with natural conditions. However, during the fallow state, the restoration of the original properties of these lands was hindered by factors such as periodic haymaking, grazing and agriculture burinig. In addition, during agricultural exploitation, the soils of the studied territory were subjected to various degrees of erosion processes. Thus, even in the case of medium-aged fallows we cannot say that the recovery process has gone far enough; we can only note the restoration trends. 
The study was carried out according to the state assignment of ISSA SB RAS.

\section{References}

1. Cramer V A, Hobbs R J and Standish R J 2008 What's new about old fields? Land abandonment and ecosystem assembly Trends Ecol. Evol. 23 104-12

2. Estel S, Kuemmerle T, Alcántara C, Levers C, Prishchepov A and Hostert P 2015 Mapping farmland abandonment and recultivation across Europe using MODIS NDVI time series Remote Sens. Environ 163 312-25

3. Kaifang Shi, Qingyuan Yang, Yuanqing Li and Xiufeng Sun 2019 Mapping and evaluating cultivated land fallow in Southwest China using multisource data Science of The Total Environment $\mathbf{6 5 4}$ 987-99

4. Pazúr R, Lieskovský J, Feranec J and Ot'ahel' J 2014 Spatial determinants of abandonment of large-scale arable lands and managed grasslands in Slovakia during the periods of post-socialist transition and European Union accession. Appl. Geography 54 118-28 DOI: 10.1016/j.apgeog.2014.07.014

5. Titlyanova A A and Sambuu A D 2016 Succession in grasslands (Novosibirsk: Publishing House SB RAS) p 191

6. Lyuri D I, Goryachkin S V, Karavaeva N A, Denisenko E A and Nefedova T G 2010 Dynamics of Russian Agricultural Lands in the 20th Century and a Postagrogenic Restoration of Vegetation and Soils (Moscow) p 416

7. Khmelev V A and Tanasienko A A 2009 Land resources of the Novosibirsk region and ways of their rational use Sibirskii Ekologicheskii Zhurnal 2 151-64

8. Report on the state and use of lands of the Novosibirsk region in 2015 year 2016 (Novosibirsk) p 202

9. Stepanov M I, Syso A I, Chumbaev A S and Mironycheva-Tokareva N P 2017 Methodical recommendations about determination of terms of stay of the parcels of land of agricultural purpose of the Novosibirsk region in a state of fallow (Novosibirsk: Science) p 20

10. Natural zoning and the current state of soils in Novosibirsk region (Atlas) 2010 (Novosibirsk) p 20

11. Miller G F 2013 Soil-ecological assessment of agricultural landscapes of forest-steppe of Prisalairye (Novosibirsk) p 16

12. Miller G F, Filimonova D A, Bezborodova A N and Solovev S V 2019 Pedologicalecological assessment of erosion-hazardous soils under young and middle-aged fallows of the South-East of Western Siberia Int. J. of Applied and Basic Research 11 26-9

13. Nekrasova O A 2008 Methods of analysis of soil organic matter. Guide to laboratory classes (Ekaterinburg) p 107

14. Galeeva L P 2012 Soil science: teaching aid (Novosibirsk: Publishing house of Novosibirsk state agrarian University) p 95

15. Litvinovich A V 2009 Postagrogenic evolution of intensively cultivated soddypodzolic soils in the west of the nonchernozemic zone Agrokhimiya 7 85-93 